\title{
Assessment on Factors Causing Female Students Attrition at Haramaya University, Ethiopia
}

\author{
Wezira Ali \\ Sociology MA, Institute of Social Sciences \\ Sakarya University (SAÜ) \\ Sakarya, Turkey. \\ Email: weziraali94@gmail.com \\ DOI: 10.31364/SCIRJ/v7.i11.2019.P1119719 \\ http://dx.doi.org/10.31364/SCIRJ/v7.i11.2019.P1119719
}

\begin{abstract}
Although numerous studies have been recording on the enhancement of female student's enrolment in higher education's of Ethiopia, much remains unknown about the striking gap of gender disparity between the enrollment and graduation rates of female students due to the excessive attrition rates at the tertiary level. This study aims to assess factors that causing female students attrition at Haramaya University. Methods to collect the data were conducted using quantitative a structured questionnaire that was distributed to the sample of female students who attend education in the College of Social Science and Humanities in the year 2016/17. Whereas, the qualitative method was held by using an in-depth interview with key personnel that contributes valuable information towards the causing factors of attrition among female students at Haramaya University. The data analyzed was a quantitative data analysis technique, such as descriptive statistics that were employed to present and summaries the data using tables. The study found a critical event in life ( pregnancy, significant person death), Tension, and separation from family as the top three personal factors for female student's attrition. Among the challenging factors in the university environment, adjustment problems with campus life(environment), influence from senior friends, instructors, and other staff members have identified as a reason for dropout. Lack of transparent grading, difficult of education as well as using assessment techniques were the top three reasons for attrition in the academic aspect.
\end{abstract}

\section{Keywords -Attrition, Gender, Tension, Dropout, Haramaya}

\section{INTRODUCTION}

Student attrition has been continued to perceived as an international concern that consequently leads to a wicked problem to higher education due to inadequate attention to the complex nature of attrition. Attrition is a proportion of students who leave or failed to succeed in their course to the end in a particular academic year. Bean(1982) defined attrition as a closure and withdrawal of student's enrollment from an institution(Bean, 1982). Similarly, (Currie et al., 2014) refer attrition as a student leaving their course without completing (graduating), getting their registered and attending their classes but failing to pass into the next semester(Currie et al., 2014).However ,Tinto (1982) argued some scholar's conclusions that state the term attrition direct with connecting to failure or inability of a person to pass into the following year or the reverse is true. Besides, he suggested that there is a need for a careful selection of the definition that could place the interest and the aims of a particular study (Tinto, 1982).

while various studies have shown progress on the enhancement of student's enrollment in higher education, much remains unknown about the causing factors of student attrition at tertiary levels. As (Hinton, 2007) suggests, the feeling of loneliness and limited contact with other students, difficulty to adjust in the new university environment, the issue of housing and arrangement are the first three contributed factors of attrition(Hinton, 2007). Moreover, Attrition has a direct link with age, gender, academic performance, critical thinking skills, a need to get advice and support and active academic participation(Pitt et al., 2012). On the other hand, some scholars have found that poor quality education systems and high school background experiences of students have a direct impact on the academic resultof students at university level. For instance, McKenzie \& Schweitzer (2001)predicated that those who joined a university with a higher score are more likely to achieve higher performance at the end of the first semester compared with those lower scores entry(McKenzie \& Schweitzer, 2001). In addition to student's former educational backgrounds, some studies have found family educational level (background) as a milestone factor for both academic achievement and failure of students in higher education (Janke, Rudert, Marksteiner, \& Dickhäuser, 2017).

Besides the fact that attrition, in general, shown as a wicked problem for both genders that seeks significant attention of scholars. The female student's attrition is high in number and at the same time, less likely to succeed in the undergraduate program to the end comparing to their male counterparts. In fact, in the last decades, gender gaps in educational achievement have been widely 
overwhelming due to the historical educational disadvantage of female students. In response to these, there has been showing drastic progress in formulating gender-sensitive policies and strategies designed to increase the enrollment of female students at higher educations. However, the attrition rate gap of female students is still widely persisted and high in number at the tertiary level of developing countries like Ethiopia.

In the last two decades, many attempts have been made by the Ethiopian government to enhance the number of underrepresented female students in Ethiopian higher education through strong intervention and implementations of alternative access policies such as affirmative action programs. Following this, as Ethiopian Education statistics Annual Abstract by Ministry of Education (MOE)( 2016),indicated regular female students enrolment in higher education is increased from 82,301 in 2012/13 to 126,673 for 2015/16. At the same time, the rate of female graduated is increased from 12,697 in 2012/13 to 22,728. However, this doesn't change the fact of the excessive attrition rate of female undergraduate students in Ethiopian universities.For instance, according to a recent study by Kassie (2018)revealed that the proportion of female academic dismissal at Addis Ababa University was higher than compared to their proportion of enrollment, graduates and honors list (Kassie, 2018).The same is true with the case in Haramaya University which has a large proportion of female attrition rates in each semester of the academic year. Even so these two higher institutions are among the oldest and top-ranked universities in Ethiopia, the proportion of female attrition is still widely existed and high in number. Therefore, there is a need and much remained to work on the formulated alternative policies to identify and minimize the main causing factors that enforce female students to leave before completing or taking their diploma in higher education institutions of Ethiopia.

\section{Statement of the Problem}

The Ethiopian government has been taking measures to enhance both the enrollment and the graduate's number of female students through formulating successive policies and strategies in all higher institutions of Ethiopia. These helped to increase the female student's enrolment rate at the higher education level. However, the implementation level of policies was limited in addressing the problem of the excessive female attrition rates at higher educations. Regarding attrition, several studies have found personal, sociopsychological, financial and academic factors as the major causes for student attrition(Hinton, 2007; Semela, 2007; Sewasew, 2014).Moreover, few studies have focused on female students attrition inEthiopian universities, but to date limited studies have studied in Haramayauniversity. Therefore, this study focused on assessing the factors that cause female students' attrition at Haramaya University.

\section{Objective of the Study}

The general objective of this study was to assess factors causing female students attrition at Haramaya University. To meet this objective, the study ought to:

- determine the personal characteristics, social, psychological, institutional and environmental factors that cause female student attrition

\section{Basic research questions}

- Whatarethepersonal and psychological factors that cause female student attrition?

- What are social and environmental factors that force female students to leave their study?

- What are the institutional factors that cause female student attrition?

\section{Methods}

This study was conducted using both quantitative and qualitative methods. Quantitative data was collected using a structured questionnaire that was distributed to 55 samples of female students who attend education in the College of Social Science and Humanities in the year 2016/17. The College is selected purposely as it is a college that the department of the researcher is available and also expect to get the information to conduct the study. Then, a respondent from each department was selected using simple random sampling. Regarding the qualitative data, the data was collected by using in-depth interviews with key personnel that contribute valuable information towards the service given to the students as well as the solution to the reduction of female student attrition. Moreover, a quantitative data analysis technique was employed. Data were presented and summarized using tables. Descriptive statistics like percentage was computed. Besides, rank order and percentage comparisons also were used.

Table 1: sample size of female students

\begin{tabular}{|l|l|}
\hline Sample of participants \\
\hline
\end{tabular}




\begin{tabular}{|l|l|l|l|}
\hline S.No & \multicolumn{1}{|c|}{ Name of Department } & $\begin{array}{c}\text { Total } \\
\text { female } \\
\text { student }\end{array}$ & $\begin{array}{c}\text { Sample } \\
\text { from } \\
\text { each } \\
\text { departme } \\
\text { nt }\end{array}$ \\
\hline 1 & Gender and Development & 46 & 20 \\
\hline 2 & Sociology & 47 & 20 \\
\hline 3 & History & 1 & 1 \\
\hline 4 & Journalism & 20 & 6 \\
\hline 5 & Geography & 2 & 1 \\
\hline 6 & $\begin{array}{l}\text { System } \\
\text { Information }\end{array}$ & 1 & 1 \\
\hline 7 & Afaan Oromo & 20 & 5 \\
\hline 8 & Urban Planning & 2 & 1 \\
\hline & Total & 139 & 55 \\
\hline
\end{tabular}

\section{Personal factors causing attrition among female students}

Result and Discussion

As presented in table 2, out of the 12 personal factors listed to the respondents, a critical event in life ( pregnancy, death of relative or family) (81.8\%) was found to be the first problem that challenge students whereas lack of study skill(38.2) was the last factor selected as a reason for attrition at Haramaya University. The second problem was found to be tension (74.5), followed by parent separation (72.7) and health problems (63.6\%) which occupy third and fourth rank, respectively. Poor communication with senior students $(61.8 \%)$ and lack of self-confidence $(60 \%)$ were other factors students attributed to their academic failure. The remaining mentioned problems are problems students reported or encountered in Haramaya University ranked in order.

Table 2: Personal factors responsible for female students' dropout (attrition)

\begin{tabular}{|l|l|l|l|}
\hline No & Personal characteristics responsible for drop out & Yes (\%) & No (\%) \\
\hline 1 & A critical event in life (pregnancy, significant person death) & 81.8 & 18.2 \\
\hline 2 & Tension & $74.6 \%$ & 25.5 \\
\hline 3 & Parent relation or separation from family & 72.7 & 27.3 \\
\hline 4 & Health problem & 63.6 & 36.4 \\
\hline 5 & Poor communication with senior students & 61.8 & 38.2 \\
\hline 6 & Lack of self confidence & 60 & 40 \\
\hline 7 & Lack of time management skill & 58.2 & 41.8 \\
\hline 8 & Lack of adequate effort & 58.2 & 41.8 \\
\hline 9 & Falling in love easily & 56.4 & 43.6 \\
\hline 10 & Not attending class properly & 50.96 & 49.5 \\
\hline 11 & Drug addiction & 49.1 & 50.9 \\
\hline
\end{tabular}




\begin{tabular}{|l|l|l|l|}
\hline 12 & Lack of study skill & 38.8 & 61.8 \\
\hline
\end{tabular}

\section{University factors responsible for dropout/Attrition}

Among the university factors, students reported that adjustment problems with campus life/environment (83.6\%) were found to be the first university factor contributing to their attrition. influence from senior friends with inappropriate behavior (70.9\%) which was the second factor, whereas the influence of instructors and other staff members as the third reason for student's problems. Further, the lack of special support services (e.g. guidance and counseling)(56.4\%) reported being the fourth factor for students to drop out. The remaining factors are lack of tutorial and consultancy services, not being interested in the subject matter and lack of special facilities like a separate library.

Table 3: University factors responsible for dropout

\begin{tabular}{|l|l|l|l|}
\hline No & University factors & Yes (\%) & No (\%) \\
\hline 1 & Adjustment problem with campus life/environment & 81.8 & 18.2 \\
\hline 2 & Influence from senior friends & $74.6 \%$ & 25.5 \\
\hline 3 & The influence from instructors and other staff members & 72.7 & 27.3 \\
\hline 4 & Lack of special support services (e.g. guidance and counseling) & 63.6 & 36.4 \\
\hline 5 & Not beinginterested in the subject matter & 61.8 & 38.2 \\
\hline 6 & Lack of self confidence & 60 & 40 \\
\hline 7 & Lack of time management skill & 58.2 & 41.8 \\
\hline 8 & Lack of adequate effort & 58.2 & 41.8 \\
\hline 9 & Falling in love easily & 56.4 & 43.6 \\
\hline 10 & Not attending class properly & 50.96 & 49.5 \\
\hline 11 & Drug addiction & 49.1 & 50.9 \\
\hline 12 & Lack of study skill & 38.8 & 61.8 \\
\hline
\end{tabular}

\section{Academic factors responsible for dropout/Attrition}

The result in table 4 show that out of 5 factors that presumed to be academic factors affecting student performance, lack of transparent grading $(81.8 \%)$ and difficulty of education $(78.2 \%)$ were the first and the second academic reason for drop out. Use of difficult assessment technique (exam, test, assignment and practice (74.5\%) as the third reason whereas the poor quality of teaching and high workload (much assignment, much credit hour, etc.) were found to be the fourth rank among academic reasons for dropout which jointly account $(63.6 \%)$.

Table 4: Academic factors causes for dropout rate

\begin{tabular}{|l|l|l|l|}
\hline No & Academic factors & Yes (\%) & $\begin{array}{l}\text { No } \\
(\%)\end{array}$ \\
\hline 1 & Lack of transparent grading & 81.8 & 18.2 \\
\hline 2 & Difficulty of education & $78.2 \%$ & 21.8 \\
\hline 3 & Use of difficult assessment techniques (exam, test, assignment, and practice) & 74.8 & 25.8 \\
\hline 4 & Lack of special support services (e.g. guidance and counseling) & 63.6 & 36.4 \\
\hline 5 & High work load (much assignment, much credit hour etc.) & 63.6 & 36.4 \\
\hline
\end{tabular}

\section{People to whom students discuss}

The result from table 5 below, put on view that friends $(65.5 \%)$ found to be the first nearer people. students would like to seek advice from or share their secret, followed by student counselors $(58.2 \%)$ and parents $(47.5 \%)$ as the second and third dependable bodies students discussed with. the remaining people students talk to include instructors (45.5\%), other family members (43.6\%), academic advisors (43.6\%) and study skill advisors.

Table 5: people to whom students discuss with when they are thinking about dropping out (withdrawing from a subject reducing load)

\begin{tabular}{|l|l|l|l|}
\hline No & Which people you discuss with & Yes $(\%)$ & No $(\%)$ \\
\hline
\end{tabular}




\begin{tabular}{|l|l|l|l|}
\hline 1 & Friends & 65.5 & 34.5 \\
\hline 2 & Student counselor & 58.2 & \\
\hline 3 & Parents & 47.3 & 41.8 \\
\hline 4 & Instructor & 45.5 & 52.7 \\
\hline 5 & Other family member & 43.6 & 54.5 \\
\hline 6 & Academic advisor & 43.6 & 56.4 \\
\hline 7 & Study skill advisor & 43.6 & 56.4 \\
\hline
\end{tabular}

\section{Circumstances making students less likely to leave}

Table 6 below revealed the possible solution that changes (make) students less likely to leave. In this regard, the top five way out students agreed were a good preparation orientation program at the beginning of the semester $(74.8 \%)$, getting better grades by working hard(72.7\%), changes to the time table in favor of students (69.\%), improvement in financial situation(63.9\%) and getting guidance and counseling service $(56.4 \%)$. The last agreed solution for student problems was found to increase support from an academic advisor $(38.2 \%)$.

Table 6: what changes in student circumstance would make them less likely to leave

\begin{tabular}{|l|l|l|l|l|}
\hline No & Items & $\begin{array}{l}\text { Agree } \\
(\mathbf{\%})\end{array}$ & Undecided (\%) & $\begin{array}{l}\text { Disagree } \\
(\mathbf{\%})\end{array}$ \\
\hline 1 & $\begin{array}{l}\text { A good preparation orientation program in the beginning of } \\
\text { the semester }\end{array}$ & 74.8 & 3.6 & 21.8 \\
\hline 2 & Getting better grades by working hard & 72.7 & 14.5 & 12.7 \\
\hline 3 & Changes to the time table in favor of students & 69.1 & 14.5 & 16.5 \\
\hline 4 & Improvement in financial situation & 63.6 & 23.6 & 12.7 \\
\hline 5 & Getting guidance and counseling service & 56.4 & 10.9 & 32.7 \\
\hline 6 & Participating in short term training & 52.7 & 29.1 & 18.2 \\
\hline 7 & Increasing support from senior students & 47.3 & 30.9 & 21.8 \\
\hline 8 & Increasing support from teaching staff & 45.5 & 16.4 & 38.2 \\
\hline 9 & Making friends on campus & 41.8 & 30.9 & 27.3 \\
\hline 10 & Increase support from academic advisor & 38.2 & 30.9 & 30.7 \\
\hline
\end{tabular}

\section{Interview results}

The researcher interviewed the university's Gender, HIV/AIDS and Special Need Issue Mainstreaming Directorate Director Mrs. EmebetBelete. The in-depth interview consisted of questions about the kind of service does the gender office gives to students. Based on the Director responses, the section gives psychological such as counseling support, academic, financial and non-financial services.

Psychologically, advice /consultation is provided for those students who face psychological and health-related problems such as depression, tension, and unintended pregnancy. Previously, there was a consulting body in the section but currently, students are referred to the university's clinic that has consulting services. Regarding academic service, the section facilitates, tutor to female students as well as a gender-related course for re-admitting female students until they re-join their regular university courses. Furthermore, the gender office gives financial (pocket money) and non-financial services like stationery and sanitary materials to students from low-income families.

\section{Discussion}

The purpose of this study was to assess personal, psychological, institutional, and environmental factors that cause female student attrition at Haramaya University. Starting from the personal and psychological factors, a critical event in life, which implies unwanted pregnancy, and significant person death was the first factor that is responsible for female student dropout. The result is in align with the findings of Semela ( 2007)who have reported pregnancy as one of a major cause that forces female students to terminate their education. This shows that the shortage of awareness on reproductive health among first-year female students that seeks successive interventions and effective health promotional activities of the university. The second problem was found to be tension followed by parent separation, or separation from family. These are all concluded under the categorizations of psychological problems that could hamper them not to concentrate on their studies. This result seems consistent with the findings of Melese \& Fenta (2009), who reported anxiety and tension as factors that contribute to student attrition. To mitigate these problems, female students should manage their time efficiently. They also need to prepare earlier to successfully achieve better results. Moreover, during exam time, female students should avoid unwanted stress since this could even hamper them not to work hard. 
As it has been indicated in university factors, adjustment problems with campus life, influence from senior friends with inappropriate behavior, and the influence from instructors and other staff members are the major top three factors for female student attrition. Regarding adjustment problems with campus life, female students should prepare themselves for the university they are going to join. They should assess the environment of the university as well as the fielded they are going to study. Unlike previous work of literature held by Buote et al., (2007) on the positive sides of making senior friends on campus, this study found the influence from senior friends with inappropriate behavior as one of a reason for drop out of first-year female students from the university.Moreover, the result of this study found the gender related problem thatFemale students face from some teaching staff. Instructors and other staff members force female students to engage in unwanted activity using grade as a weapon. This may force female students to drop out of their studies.

The top three academic factors that are causes for female student attrition are lack of transparent grading by instructors and registrar officers, the difficulty of education, and the use of difficult assessment techniques such as exams, tests, and assignments.

In this study, it was found out that friends, student councilor, parents, instructors were nearest people to students would like to seek advice from or share their secret when they were thinking of dropping out. Moreover, with regard to circumstances that would make students less likely to leave, the study found out that a good preparation/orientation program at the beginning of the semester, getting better grades by working hard, changes to the time table in favor of students, improvement in financial situation and getting guidance and counseling services were the top five possible solutions that reduce female student attrition problem.

\section{Conclusion and Recommendations}

\section{Conclusion}

- A critical event in life (pregnancy, significant person death), tension, separation of family, health problem, poor communication with senior students were the top five factors that threatened student's academic performance at Haramaya University.

- As it has been indicated in the university factors, adjustment problems with campus life/environment, influence from senior friends with inappropriate behavior, the influence from instructors, and other staff members were found to be the major challenging factors in the university environment.

- The outcome of the present study also show lack of transparent grading, the difficulty of education, use of different assessment technique, poor quality of teaching and high workload were the top five reasons for attrition in academic aspect.

- In this study, it was found out that friends, student counselors, parents, instructors were nearest people students would like to seek advice from or share their secret when they were thinking of dropping out.

- Concerning circumstances that would make students less likely to leave, this study found out that a good preparation(orientation program at the beginning of the semester, getting better grades by working hard, changes to the timetable in favor of students were the top three possible solutions that reduce students attrition problems.

- Gender office in Haramayauniversity gives different service interims of financial, non-financial, academic and psychological services.

\section{Recommendations}

- The university should prepare a well-organized orientation program at the university, college, and department level that helps female students understand the university environment.

- The university should also strengthen the counseling institutions that give continuous guidance about academic life as well as gender-related issues.

- Regarding academic factors, the instructors should provide appropriate assistance to female students as well as should make their grading system transparent.

- The university should take disciplinary action on those instructors with inappropriate behavior.

- Female students on their side should be determined to their goal, should manage their time and work hard, and avoid friends with misconduct.

\section{REFERENCE}

Bean, J. P. (1982). Student attrition, intentions, and confidence: Interaction effects in a path model. Research in Higher Education, 17(4), 291-320.

Buote, V. M., Pancer, S. M., Pratt, M. W., Adams, G., Birnie-Lefcovitch, S., Polivy, J., \& Wintre, M. G. (2007). The importance of friends: Friendship and adjustment among 1st-year university students. Journal of Adolescent Research, 22(6), 665-689. 
Currie, K., McCallum, J., Murray, J., Scott, J., Strachan, E., Yates, L., \& Wright, M. (2014).Developing a national computerised absence monitoring and management system to reduce nursing student attrition: Evaluation of staff and student perspectives.Nurse Education Today, 34(5), 738-743.

Hinton, L. (2007). Causes of attrition in first year students in science foundation courses and recommendations for intervention.Studies in Learning, Evaluation, Innovation and Development, 4(2), 13-26.

Janke, S., Rudert, S. C., Marksteiner, T., \& Dickhäuser, O. (2017). Knowing one's place: Parental educational background influences social identification with academia, test anxiety, and satisfaction with studying at university. Frontiers in Psychology, 8 , 1326.

Kassie, K. (2018). Gender difference in higher education in Ethiopia: A case of Addis Ababa University (AAU). Africa Review, 10(2), $157-172$.

McKenzie, K., \& Schweitzer, R. (2001). Who succeeds at university? Factors predicting academic performance in first year Australian university students.Higher Education Research \& Development, 20(1), 21-33.

Melese, W., \& Fenta, G. (2009). Trend and causes of female students dropout from teacher education institutions of Ethiopia: The case of Jimma University. Ethiopian Journal of Education and Sciences, 5(1).

Pitt, V., Powis, D., Levett-Jones, T., \& Hunter, S. (2012). Factors influencing nursing students' academic and clinical performance and attrition: An integrative literature review. Nurse Education Today, 32(8), 903-913.

Semela, T. (2007).Identification of factors contributing to gender disparity in an Ethiopian university.Eastern Africa Social Science Research Review, 23(2), 71-93.

Sewasew, D. T. (2014). Attrition causes among university students: The case of Gondar University, Gondar, north west Ethiopia. Innov. J. Soc. Sci, 2, 27-34.

Tinto, V. (1982).Defining dropout: A matter of perspective.New Directions for Institutional Research, 1982(36), 3-15. 